\title{
The socio-demographic characteristics and health needs of incarcerated women applying to a transitional housing re- entry program
}

\author{
Margaret Raber ${ }^{1 *}$, Vanessa Schick ${ }^{1}$, Esha Hansoti ${ }^{2}$, Andrea Link ${ }^{2,3}$, Isabel Roth ${ }^{1}$ and Alycia Welch ${ }^{2}$ \\ ${ }^{1}$ University of Texas School of Public Health, 1200 Pressler St. Houston, TX, USA 77030 \\ ${ }^{2}$ Angela House, 6725 Reed Rd., Houston, TX, USA 77087 \\ ${ }^{3}$ Baylor College of Medicine, 1 Baylor Plaza, Houston, TX, USA 77030
}

\section{Background}

The number of women under the jurisdiction of local, state, and federal correctional authorities has risen dramatically in the last several decades, increasing 646 percent from 1980 to 2010 [1]. As women are released from correctional facilities, they face legal restrictions, limited access to federal support programs and social stigma [2]. These constraints can impact almost all parts of an individual's social functioning, including one's ability to obtain adequate housing, food, employment, education, credit cards, loans, parental rights, travel, and occupational licensing [2], increasing the likelihood of re-arrest [3].

Most literature on the challenges of re-entry focuses on the experience of all inmates, which may be skewed towards males, given the greater number of men in the criminal justice system [4]. Women face unique challenges to avoiding re-arrest [5]. In addition to the barriers facing those with criminal records trying to reenter society, many formerly incarcerated women have intersecting identities that can lead to multiple layers of discrimination and inequality including racism, poverty and marginalization [6]. This further limits access to resources women need to reintegrate into communities and avoid rearrest. Female inmates often come from already vulnerable groups, with most being young in age and economically disenfranchised; about two-thirds are women of color [4].

There is evidence that women are impacted by poor health during and after incarceration. Previous incarceration has been independently linked to increased rates of chronic disease and poor health care access for both genders $[7,8]$. However, incarcerated women have significantly higher rates of asthma, hypertension, diabetes, cancer, arthritis, hepatitis, and cirrhosis as well as depression, bipolar disorder, posttraumatic stress, anxiety, personality disorders, and drug abuse compared to incarcerated men [9]. The experience of imprisonment can increase the likelihood of developing new or exacerbating existing mental health issues, such as stress, anxiety and depression, which may further increase risk for major chronic conditions [8].

Approximately $95 \%$ of current inmates in state prisons will be released into communities [10] making formerly incarcerated, low resource women an important intervention target. Without adequate supports and services to address their unique needs upon release, women are likely to be rearrested and return to incarceration. This creates a growing burden on the correctional system, with the cost of incarceration over $\$ 21,000$ per year per inmate [11]. It also creates a growing burden on the healthcare system. Increased risk for a myriad of physical and mental health issues, combined with the social and economic hardships that often come with a criminal record can lead to "super-utilization" of the healthcare system by this group [12] High rates of somatic and psychological disease, widespread historical drug use, and the extensive range of medication use demonstrated in the current study highlight the complexity of health issues in this population.

By targeting formerly incarcerated women with transitional services that include comprehensive addiction and mental health treatment, preventive medical services and family support, we can potentially reduce re-incarceration and emergency utilization of our healthcare system. However, a deeper understanding of previously incarcerated women's complex mental and physical needs is essential to community re-entry program success [13]. This study examines the socio-demographic characteristics, physical and mental health needs, and historical conviction and drug use of applicants to a transitional housing and re-entry program based in Houston, Texas.

\section{Methods}

Self- reported demographic, health and historical conviction information was reviewed and extracted from paper applications to a female-only supportive transitional housing program, Angela House, spanning 2013 to 2016. Angela House targets women exiting the prison system at high risk of homelessness.

Residency at Angela House is a 4-month commitment and includes: residence, meals, group, individual, and shame resilience therapy, education support, job training, spiritual guidance, creative arts, 12 step recovery, support services, and a trust account system to facilitate saving for future independent living. Angela House also offers a health and wellness program which includes classes and workshops taught through a service learning model collaboration with a local medical school, trauma-specific counseling, healing through the arts, peer support and extra career counseling. The overall goal of

${ }^{*}$ Correspondence to: Margaret Raber, University of Texas School of Public Health, 1200 Pressler St. Houston, TX, USA, 77030; Tel: (713) 702-4801; E-mail: Margaret.p.raber@uth.tmc.edu

Received: January 22, 2018; Accepted: February 26, 2018; Published: March 02,2018 
Angela House is to reduce recidivism among their clients. Women in correctional facilities (jails and prisons) submit applications directly to Angela House before their discharge date. Angela House only considers applicants over the age of 17, and cannot accept those on probation or parole due to city restrictions, but there are no other specific criteria for applying.

The applications contain questions on demographics, medical needs, prior convictions, and addiction history. They also include openended questions related to personal goals, which were not analyzed for this project. Demographic questions included age, marital status, parenting status, last grade completed, and supplemental security income history. Conviction information included overall number of times incarcerated and types of convictions, as well as specific questions regarding arrests for bodily injury.

Medical information included open-ended, self-reported medical needs through a single item (What are your medical needs, if any?), current medications (Please list medications you are currently taking), previous hospitalizations, as well as physical and sexual abuse history. Substance use questions consisted of types of drugs or alcohol ever used as well as drugs of choice. For both of these questions, applicants were given a list of substances to choose from (e.g., marijuana, cocaine, PCP) and encouraged to select all that apply. Slight variation in the application form over time prohibited a meaningful analysis of every question ever included on the form, but all health-related needs questions were included in the analysis.

Inclusion criteria for reviewed applications included: applicants 18 years of age or older, female, and having served at least a 90 day term in prison or jail. Exclusion criteria included: application documents completed by men, those completed in any language other than English, or those deemed unreadable by study staff. Applicant information was extracted from 177 documents and analyzed for this study. Each document represents one unique applicant and those that applied multiple times or used aliases were removed during data entry. Data was entered into an electronic format by two members of the research team and ten percent of documents were double checked for accuracy in transcription.

De-identified applications were analyzed using descriptive statistics. Contingency tables were generated based on number of convictions to explore differences between first time and repeat offenders with regard to medical needs, drug use history, and other factors. Differences between groups were investigated using Pearson's chi-squared and/or Fisher's exact test. The Institutional Review Board of [blinded] reviewed and approved this protocol.

\section{Results}

\section{Demographics}

The socio-demographic characteristics of the sample are shown in Table 1. Participants ranged in age from 19 - 59 years old with the majority (66\%) between the ages of $30-49$. The mean age was 38.6 years. Only 15.1 percent of participants were first time offenders, with 47.2 percent noting over six incarcerations in their lifetime. Just over 18 percent of applicants had any college education (including "some college" or "college graduate"); many did not complete high school or an equivalent (34.6\%). Most applicants (91.7\%) reported that they were currently single, widowed, divorced or separated. Those with more than one conviction were significantly less likely $(\mathrm{X} 2=5.64$; $\mathrm{p}=.02$ ) to report having children under 18 , compared to first offenders. Despite the difference between the groups, more than half of the
Table 1. Socio-demographic Characteristics.

\begin{tabular}{|c|c|c|c|c|c|c|c|c|c|c|}
\hline \multirow{3}{*}{$\begin{array}{l}\text { Age } \\
18-24\end{array}$} & \multirow{2}{*}{\multicolumn{2}{|c|}{$\begin{array}{l}\text { Total } \\
\%(\mathrm{~N})\end{array}$}} & \multicolumn{8}{|c|}{ Times Incarcerated } \\
\hline & & & \multicolumn{2}{|c|}{1} & \multicolumn{2}{|c|}{$2-5$} & \multicolumn{2}{|c|}{$6-10$} & \multicolumn{2}{|c|}{$11+$} \\
\hline & 9.6 & (14) & 9.1 & (2) & 10.9 & $(6)$ & 15.0 & (6) & 0.0 & $(0)$ \\
\hline $25-29$ & 11.0 & (16) & 18.2 & (4) & 12.7 & (7) & 7.5 & (3) & 6.9 & (2) \\
\hline $30-39$ & 66.4 & (51) & 45.5 & (10) & 25.5 & (14) & 40.0 & (16) & 37.9 & (11) \\
\hline $40-49$ & 31.5 & (46) & 22.7 & (5) & 34.5 & (19) & 27.5 & (11) & 37.9 & (11) \\
\hline $50-59$ & 13.0 & (19) & 4.5 & (1) & 16.4 & (9) & 10.0 & (4) & 17.2 & (5) \\
\hline \multicolumn{11}{|l|}{ Education } \\
\hline Less than high school & 10.3 & (14) & 5.0 & (1) & 12.0 & (6) & 10.5 & (4) & 10.7 & (3) \\
\hline Some high school & 24.3 & (33) & 15.0 & (3) & 22.0 & (11) & 36.8 & (14) & 17.9 & (5) \\
\hline High school graduate & 47.1 & (64) & 60.0 & (12) & 42.0 & (21) & 39.5 & (15) & 57.1 & (16) \\
\hline College & 18.4 & $(25)$ & 20.0 & (4) & 24.0 & (12) & 13.2 & (5) & 14.3 & (4) \\
\hline \multicolumn{11}{|l|}{ Marriage Status } \\
\hline Divorced & 21.2 & (31) & 27.3 & (6) & 21.8 & (12) & 15.0 & (6) & 24.1 & (7) \\
\hline Married & 8.2 & (12) & 0.0 & (0) & 10.9 & (6) & 2.5 & (1) & 17.2 & (5) \\
\hline Separated & 13.0 & (19) & 9.1 & (2) & 14.5 & (8) & 15.0 & (6) & 10.3 & (3) \\
\hline Single & 54.1 & (79) & 63.6 & (14) & 50.9 & (28) & 62.5 & (25) & 41.4 & (12) \\
\hline Widowed & 3.4 & $(5)$ & 0.0 & $(0)$ & 1.8 & (1) & 5.0 & (2) & 6.9 & $(2)$ \\
\hline \# With Children $<18$ & 57.2 & (83) & 81.0 & (17) & 55.6 & (30) & 48.8 & $(20)$ & 55.2 & (16) \\
\hline \multicolumn{11}{|l|}{$\#$ of Children $<18$} \\
\hline 1 & 31.8 & (27) & 29.4 & (5) & 35.5 & (11) & 25.0 & (5) & 35.3 & (6) \\
\hline 2 & 30.6 & (26) & 29.4 & (5) & 38.7 & (12) & 25.0 & (5) & 23.5 & (4) \\
\hline 3 & 23.5 & (20) & 29.4 & (5) & 16.1 & (5) & 30.0 & (6) & 23.5 & (4) \\
\hline $4+$ & 14.1 & (12) & 11.8 & (2) & 9.7 & (3) & 20.0 & (4) & 17.6 & (3) \\
\hline
\end{tabular}

entire sample (57.2\%) reported having at least one child. Further, 68.2 percent of those with children reported having two or more, and 14.1 percent reported having more than three children under the age of 18. The majority $(80 \%)$ of participants reported never receiving any supplemental security income / disability income.

\section{Conviction Types}

Participants reported a range of lifetime conviction types with possession of a controlled substance, prostitution / solicitation, and forgery / fraud / theft listed as the most common convictions (Table 2). More minor offenses, such as trespassing, criminal mischief, tickets and traffic violations, evading, public intoxication and parole violations were also relatively common (34.7\%). A large portion of the sample (83.6\%) listed a drug-related offense (including possession, delivery, manufacturing, distribution, and paraphernalia). For first time offenders, 50.0 percent reported forgery / fraud / theft convictions and a further 31.8 percent reported robbery / burglary offenses. Only 27.2 percent of first time offenders reported a drug related offense, compared to 93.6 percent of those with two or more incarcerations.

\section{Health and Wellness}

The self reported medical needs of participants include physical and psychological ailments, as well as substantial prescription drug usage (Table 3). Over two thirds (67.3\%) of the sample noted at least one medical need and 66.7 percent reported being on at least one medication. General mental health, depression, respiratory disorders, and cardiovascular related diseases were the most common in the sample. Over half (57.1\%) of first time offenders reported depression compared to 19.0 percent of those with multiple incarcerations. Over 6 percent of participants stated that they were currently living with HIV. Medication use was high, with 29.3 percent of the entire sample and 40 percent of first time offenders reporting current anti-depressant prescription drug use. Selective serotonin re-uptake inhibitors (SSRIs, 17.0\%) and antipsychotics (17.0\%) were the most common specific prescriptions reported. Anticonvulsant (10.9\%) usage was 
Table 2. Types of Convictions

\begin{tabular}{|c|c|c|c|c|c|c|c|c|c|c|c|c|c|c|}
\hline \multirow{3}{*}{$\begin{array}{l}\text { Incarceration Type } \\
\text { Possession of Controlled Substance* }\end{array}$} & \multirow{2}{*}{\multicolumn{2}{|c|}{$\begin{array}{c}\text { Total } \\
\% \text { (N) }\end{array}$}} & \multicolumn{8}{|c|}{ Times Incarcerated } & \multicolumn{4}{|c|}{ Times Incarcerated } \\
\hline & & & \multicolumn{2}{|c|}{1} & \multicolumn{2}{|c|}{$2-5$} & \multicolumn{2}{|c|}{ 6-10 } & \multicolumn{2}{|c|}{$11+$} & \multicolumn{2}{|c|}{1} & \multicolumn{2}{|c|}{$2+$} \\
\hline & 65.3 & (96) & 22.7 & $(5)$ & 56.4 & (31) & 82.9 & (34) & 89.7 & (26) & 22.7 & (5) & 72.8 & (91) \\
\hline Forgery, Fraud and Theft & 45.6 & (67) & 50.0 & (11) & 43.6 & (24) & 41.5 & (17) & 51.7 & (15) & 50.0 & (11) & 44.8 & (56) \\
\hline Prostitution / Solicitation & 44.2 & $(65)$ & 0.0 & $(0)$ & 34.5 & (19) & 53.7 & (22) & 82.8 & (24) & 0.0 & $(0)$ & 52.0 & $(65)$ \\
\hline Robbery / Burglary & 17.0 & (25) & 31.8 & (7) & 12.7 & (7) & 19.5 & (8) & 10.3 & (3) & 31.8 & (7) & 14.4 & (18) \\
\hline Delivery / Manufacturing / Distribution & 16.3 & (24) & 4.5 & (1) & 12.7 & (7) & 17.1 & (7) & 31.0 & (9) & 4.5 & (1) & 18.4 & (23) \\
\hline Trespassing and Criminal Mischief & 14.3 & $(21)$ & 0.0 & $(0)$ & 3.6 & $(2)$ & 17.1 & (7) & 41.4 & $(12)$ & 0.0 & $(0)$ & 16.8 & (21) \\
\hline Assault (Any) & 11.6 & (17) & 0.0 & $(0)$ & 12.7 & (7) & 9.8 & (4) & 20.7 & (6) & 0.0 & $(0)$ & 13.6 & (17) \\
\hline Tickets and Traffic Violations & 8.8 & (13) & 4.5 & (1) & 5.5 & (3) & 2.4 & (1) & 27.6 & (8) & 4.5 & (1) & 9.6 & (12) \\
\hline Child Abandonment, Endangerment, Injury & 7.5 & (11) & 0.0 & $(0)$ & 10.9 & (6) & 9.8 & (4) & 3.4 & (1) & 0.0 & $(0)$ & 8.8 & (11) \\
\hline Parole / Probation Violation & 5.4 & $(8)$ & 4.5 & (1) & 9.1 & $(5)$ & 2.4 & (1) & 3.4 & (1) & 4.5 & (1) & 5.6 & (7) \\
\hline Public Intoxication & 4.8 & (7) & 0.0 & $(0)$ & 0.0 & $(0)$ & 9.8 & (4) & 10.3 & (3) & 0.0 & $(0)$ & 5.6 & (7) \\
\hline Driving While Intoxicated & 4.8 & (7) & 9.1 & (2) & 1.8 & (1) & 7.3 & (3) & 3.4 & (1) & 9.1 & (2) & 4.0 & $(5)$ \\
\hline Ever Arrested for Bodily Injury & 21.4 & (22) & 11.8 & (2) & 16.2 & (6) & 25.9 & (7) & 31.8 & (7) & 11.8 & (2) & 23.3 & $(20)$ \\
\hline
\end{tabular}

Table 3. Self reported health issues and medications.

\begin{tabular}{|c|c|c|c|c|c|c|}
\hline \multirow{3}{*}{\begin{tabular}{|l|} 
Medical Needs \\
Anxiety \\
\end{tabular}} & \multirow{2}{*}{\multicolumn{2}{|c|}{$\begin{array}{c}\text { Total } \\
\%(\mathbf{N}) \\
\end{array}$}} & \multicolumn{4}{|c|}{ Times Incarcerated } \\
\hline & & & \multicolumn{2}{|c|}{1} & \multicolumn{2}{|c|}{$2+$} \\
\hline & 2.7 & (4) & 4.5 & (1) & 2.4 & (3) \\
\hline Asthma / COPD & 10.2 & (15) & 9.1 & (2) & 10.4 & (13) \\
\hline Back issues / Arthritis & 8.2 & (12) & 9.1 & (2) & 8.0 & $(10)$ \\
\hline Bipolar & 8.2 & (12) & 4.5 & (1) & 8.8 & (11) \\
\hline Depression & 12.9 & (19) & 18.2 & (4) & 12.0 & (15) \\
\hline General Mental Health & 17.0 & $(25)$ & 9.1 & (2) & 18.4 & (23) \\
\hline $\begin{array}{l}\text { Heart disease / hypertension / } \\
\text { blood pressure }\end{array}$ & 8.8 & (13) & 4.5 & (1) & 9.6 & (12) \\
\hline Hepatitis C & 2.7 & (4) & 0.0 & $(0)$ & 3.2 & (4) \\
\hline HIV & 6.1 & (9) & 4.5 & (1) & 6.4 & (8) \\
\hline PTSD & 3.4 & (5) & 0.0 & $(0)$ & 4.0 & (5) \\
\hline Seizure & 4.8 & (7) & 4.5 & (1) & 4.8 & (6) \\
\hline Thyroid Issues & 4.1 & (6) & 0.0 & (0) & 4.8 & (6) \\
\hline Vision / Hearing / Dental & 6.8 & (10) & 4.5 & (1) & 7.2 & (9) \\
\hline \multicolumn{7}{|l|}{ Current Medications } \\
\hline HIV Medications & 5.4 & (8) & 0.0 & $(0)$ & 6.4 & $(8)$ \\
\hline Any Anti Depressant & 29.3 & (43) & 36.4 & (8) & 28.0 & (35) \\
\hline$T C A$ & 6.8 & (10) & 0.0 & $(0)$ & 8.0 & (10) \\
\hline SSRI & 17.0 & $(25)$ & 31.8 & (7) & 14.4 & (18) \\
\hline SNRI & 0.7 & (1) & 0.0 & $(0)$ & 0.8 & (1) \\
\hline SARI & 8.2 & (12) & 0.0 & $(0)$ & 9.6 & (12) \\
\hline Sedatives & 2.0 & (3) & 0.0 & $(0)$ & 2.4 & (3) \\
\hline Narcotic Pain Relievers & 1.4 & (2) & 0.0 & $(0)$ & 1.6 & (2) \\
\hline Anticonvulsant & 10.9 & (16) & 4.5 & (1) & 12.0 & (15) \\
\hline Antipsychotic & 17.0 & (25) & 4.5 & (1) & 19.2 & (24) \\
\hline $\begin{array}{l}\text { Heart / Blood Pressure } \\
\text { Medication }\end{array}$ & 8.2 & (12) & 4.5 & (1) & 8.8 & (11) \\
\hline Ever hospitalized & 58.3 & $(56)$ & 36.4 & (4) & 61.2 & (52) \\
\hline $\begin{array}{l}\text { Ever victim of sexual / physical } \\
\text { abuse }\end{array}$ & 70.0 & (91) & 68.8 & (11) & 70.2 & (80) \\
\hline
\end{tabular}

also reported. Slightly more than half the sample reported ever being hospitalized for any reason (58.3\%). The majority (70.0\%) reported a history of sexual and/or physical abuse.

\section{Substance Use History}

A lifetime history of drug and alcohol was common (Table 4) as all but one applicant indicated prior drug or alcohol use (99.3\%); 70.1 percent reported crack usage, 66.7 percent reported alcohol use and 68.7 percent reported marijuana use. Self reported "drug of choice" information was also collected. Crack was also the most popular drug of choice with 54.4 percent of all applicants. First time offenders were significantly less likely $(\mathrm{p}<.0001)$ to report ever using (test value $=$ 27.647 ) or currently preferring (test value $=17.350$ ) crack cocaine than those with more than one incarceration. First time offenders were more likely to indicate cocaine, prescriptions or methamphetamines as drugs of choice compared to multiple offenders, although the differences were not statistically significant.

\section{Discussion}

Despite the increasing number of women exiting correctional facilities, relatively few re-entry programs meet the needs of female former inmates [14]. This study reveals several notable trends with regard to the demographics, medical needs, and historical drug usage of applicants to a community re-entry program that can help inform future programming and target resource gaps for this population. The specific social and medical conditions women face, and the marginalization associated with incarceration, highlight the need for comprehensive, multi-leveled programming [15]. Re-entry and transition programs should be tailored to women exiting incarceration, with the social, psychological, and medical needs of the end-users taken into consideration during program development.

Basic housing and some measure of socioeconomic security are vital to successful societal reentry [16]. Our data found most (80\%) women in the sample have never received any type of supplemental security income, possibly due to the high level of multiple incarcerations (85\% listed more than one incarceration and $46.9 \%$ report more than 6 incarcerations). Unlike other working poor, many individuals with criminal records are barred from receiving government financial or food assistance [17]. These restrictions on public assistance disproportionately affect women, as females are more likely to be primary child caretakers and are more likely to suffer economic marginalization [18]. This was apparent in our sample, in which nearly 60 percent reported having children under 18 , and of those 68.2 percent had two or more children and 37.6 percent had three or more children. Further, the majority of our sample reported being currently single, suggesting they may have limited support from co-parents.

Beyond basic housing and economic issues, treatment of the complex health issues plaguing women exiting incarceration is a priority for successful reintegration into society. One of the more striking pieces of data revealed by this study includes the rate of prescription antidepressant usage in the sample (29.3\%) and prescription antipsychotic 
Table 4. Lifetime drug use and preferences.

\begin{tabular}{|c|c|c|c|c|c|c|c|c|c|c|c|c|c|c|}
\hline \multirow{3}{*}{\begin{tabular}{|l|} 
Lifetime Use \\
Alcohol \\
\end{tabular}} & \multirow{2}{*}{\multicolumn{2}{|c|}{$\begin{array}{c}\text { Total } \\
\%(\mathrm{~N})\end{array}$}} & \multicolumn{8}{|c|}{ Times Incarcerated } & \multicolumn{4}{|c|}{ Times Incarcerated } \\
\hline & & & \multicolumn{2}{|c|}{1} & \multicolumn{2}{|c|}{$2-5$} & \multicolumn{2}{|c|}{ 6-10 } & \multicolumn{2}{|c|}{$11+$} & \multicolumn{2}{|c|}{1} & \multicolumn{2}{|c|}{$2+$} \\
\hline & 66.7 & $(98)$ & 72.7 & $(16.0)$ & 63.6 & $(35.0)$ & 65.9 & $(27.0)$ & 69.0 & $(20.0)$ & 72.7 & $(16.0)$ & 65.6 & $(82.0)$ \\
\hline Amphetamine & 4.8 & (7) & 4.5 & $(1.0)$ & 5.5 & $(3.0)$ & 4.9 & $(2.0)$ & 3.4 & $(1.0)$ & 4.5 & $(1.0)$ & 4.8 & $(6.0)$ \\
\hline Cocaine & 55.1 & $(81)$ & 45.5 & $(10.0)$ & 50.9 & $(28.0)$ & 48.8 & $(20.0)$ & 79.3 & $(23.0)$ & 45.5 & $(10.0)$ & 56.8 & (71.0) \\
\hline Crack & 70.1 & (103) & 22.7 & $(5.0)$ & 65.5 & $(36.0)$ & 80.5 & $(33.0)$ & 100.0 & $(29.0)$ & 22.7 & $(5.0)$ & 78.4 & (98.0) \\
\hline Heroin & 19.7 & $(29)$ & 27.3 & $(6.0)$ & 12.7 & $(7.0)$ & 12.2 & $(5.0)$ & 37.9 & $(11.0)$ & 27.3 & $(6.0)$ & 18.4 & $(23.0)$ \\
\hline Inhalant & 4.8 & (7) & 9.1 & $(2.0)$ & 3.6 & $(2.0)$ & 2.4 & $(1.0)$ & 6.9 & $(2.0)$ & 9.1 & $(2.0)$ & 4.0 & $(5.0)$ \\
\hline LSD & 4.1 & (6) & 4.5 & $(1.0)$ & 1.8 & $(1.0)$ & 4.9 & $(2.0)$ & 6.9 & $(2.0)$ & 4.5 & $(1.0)$ & 4.0 & $(5.0)$ \\
\hline Marijuana & 68.7 & (101) & 63.6 & $(14.0)$ & 61.8 & $(34.0)$ & 70.7 & $(29.0)$ & 82.8 & $(24.0)$ & 63.6 & $(14.0)$ & 69.6 & $(87.0)$ \\
\hline Methamphetamine & 32.7 & $(48)$ & 31.8 & $(7.0)$ & 36.4 & $(20.0)$ & 24.4 & $(10.0)$ & 37.9 & $(11.0)$ & 31.8 & $(7.0)$ & 32.8 & (41.0) \\
\hline $\mathrm{PCP}$ & 12.2 & (18) & 9.1 & $(2.0)$ & 7.3 & $(4.0)$ & 9.8 & $(4.0)$ & 27.6 & $(8.0)$ & 9.1 & $(2.0)$ & 12.8 & (16.0) \\
\hline Prescriptions & 27.2 & (40) & 27.3 & $(6.0)$ & 21.8 & $(12.0)$ & 24.4 & $(10.0)$ & 41.4 & $(12.0)$ & 27.3 & $(6.0)$ & 27.2 & (34.0) \\
\hline \multicolumn{15}{|l|}{ Drug of Choice } \\
\hline Alcohol & 11.6 & (17) & 9.1 & $(2.0)$ & 9.1 & $(5.0)$ & 12.2 & $(5.0)$ & 17.2 & $(5.0)$ & 9.1 & $(2.0)$ & 12.0 & $(15.0)$ \\
\hline Marijuana & 12.2 & (18) & 13.6 & $(3.0)$ & 14.5 & $(8.0)$ & 14.6 & $(6.0)$ & 3.4 & $(1.0)$ & 13.6 & (3.0) & 12.0 & $(15.0)$ \\
\hline Cocaine & 8.2 & (12) & 18.2 & $(4.0)$ & 10.9 & $(6.0)$ & 0.0 & $(.0)$ & 6.9 & $(2.0)$ & 18.2 & $(4.0)$ & 6.4 & $(8.0)$ \\
\hline Crack & 54.4 & $(80)$ & 13.6 & (3.0) & 50.9 & $(28.0)$ & 68.3 & $(28.0)$ & 72.4 & $(21.0)$ & 13.6 & $(3.0)$ & 61.6 & (77.0) \\
\hline Heroin & 6.1 & (9) & 4.5 & $(1.0)$ & 7.3 & $(4.0)$ & 2.4 & $(1.0)$ & 10.3 & $(3.0)$ & 4.5 & $(1.0)$ & 6.4 & $(8.0)$ \\
\hline Prescriptions & 9.5 & (14) & 31.8 & (7.0) & 9.1 & $(5.0)$ & 2.4 & $(1.0)$ & 3.4 & $(1.0)$ & 31.8 & $(7.0)$ & 5.6 & $(7.0)$ \\
\hline Methamphetamine & 14.3 & (21) & 22.7 & $(5.0)$ & 14.5 & $(8.0)$ & 12.2 & $(5.0)$ & 10.3 & $(3.0)$ & 22.7 & $(5.0)$ & 12.8 & $(16.0)$ \\
\hline $\mathrm{PCP}$ & 3.4 & $(5)$ & 4.5 & $(1.0)$ & 1.8 & $(1.0)$ & 2.4 & $(1.0)$ & 6.9 & $(2.0)$ & 4.5 & $(1.0)$ & 3.2 & $(4.0)$ \\
\hline
\end{tabular}

usage $(17.0 \%)$. These figures are in line with a Bureau of Justice Statistics Special Report on the mental health of incarcerated people, which identified at least one major depressive disorder symptoms in over $60 \%$ of inmates. The report also found women had higher rates of mental health problems than male inmates, suggesting the depressive symptoms in women may be even higher [19].

Mental health issues, such as depression, that are left untreated, or improperly treated, may impact one's ability to readjust to normal society. Upon release from incarceration, it is unclear if and how antidepressant medications are discontinued. Discontinuation of many anti-depressants can lead to a range of symptoms including physical and psychosomatic distress that may compromise societal reentry efforts [20]. Programs supporting immediate medical linkage after release from incarceration may decrease the likelihood of recidivism [21]. Mental health counseling and careful monitoring of antidepressant usage is important for this population.

High rates of physical / sexual abuse (70\%) in the sample further support the need for counseling services. The rate of historical abuse in the present sample was higher than national statistics, which show 48 percent of women report being physically or sexually abused prior to incarceration [19]. It should also be noted that the estimate of physical and sexual abuse may be conservative given the barriers to self-reported abuse and variability in definitions used to operationalize such abuse. In fact, our finding is more in line with other studies that show much higher rates of abuse [22].

Highly addictive, illegal drug usage was reported by the majority of the sample with 70 percent noting crack use and 55.1 percent noting cocaine use. Crack was the most common drug of choice for those with more than one conviction (61.6\%) compared to first offenders (13.6\%). This may suggest some connection between crack addiction and multiple offenses. For example, crack cocaine usage may be used to cope with the harsh realities that face women upon release. It is also one of the least expensive drugs and may therefore be an indicator of their deteriorating economic condition. This finding further highlights the importance of targeting drug dependency in the context of recidivism prevention.
Current reentry programming predominantly focuses on social factors influencing recidivism, such as employment and education; relatively few integrate healthcare or counseling [14]; However, the breadth of needs described here indicate the necessity for a more integrative, biopsychosocial approach for successful reentry of formerly incarcerated populations into society. Programs must address the high prevalence of addiction, serious mental health conditions, chronic disease, vocational and educational training needs, trauma and abuse, and socioeconomic insecurity. Angela House is one such program, which includes linkage to specialized medical services and counseling, as well as education and job training. This analysis has highlighted the necessity of Angela House's many wrap-around services.

\section{Limitations}

Although Angela House is open to all women 18 and over, those that apply may be different from the general female incarcerated population. Angela House requires a substantial time commitment and rigorous programming schedule, suggesting that applicants to the program are ready and able to make a substantial life change. Although race information was not collected, the form was only available in English and therefore non-English speakers were unlikely to apply. The sample mean age of 38.6 was only slightly above the Texas prison mean female age of 37.3 [23]. The HIV rate in Texas among incarcerated women is $1.54 \%$, compared to $6.1 \%$ in our sample [24]. This suggests applicants to the Angela House program may be slightly older and more likely to have HIV than the general female incarcerated population in the state. Although this is a limitation to the study, it also highlights the especially vulnerable nature of those seeking transitional housing.

\section{Conclusion}

This study reviewed applications to a women's community transitional facility and found high rates of serious medical need and prescription medication use. Women exiting the criminal justice system have complex biopsychosocial needs. Programs targeting this population must go beyond the basic need for transitional housing to include comprehensive wrap-around services that are tailored to the needs of formerly incarcerated women. Policymakers should weigh 
the cost of comprehensive services against the price of repeated reincarcerations and the continuation of an intergenerational cycle of unmet needs. Further research is needed to understand how this population's complex needs can be adequately addressed by evidencebased programming.

\section{Funding}

This work was supported by the Robert Wood Johnson Foundation, Award Number 73668. MR is supported by the National Cancer Institute of the National Institutes of Health, Award Number R25CA057730 (PI: Shine Chang, PhD). The content is solely the responsibility of the authors and does not necessarily represent the official views of the NIH. The authors would like to acknowledge the University of Texas (UTHealth) School of Public Health and Angela House for their support of this project.

\section{Acknowledgment}

The authors would like to thank all Angela House residents and staff, especially founder Sister Maureen O'Connell, for their support of this project. We thank all applicants that were included in this study. Drs. Linda Highfield, Catherine Troisi and Paula Stigler-Granados assisted in the early conceptualization of this study.

\section{References}

1. Mauer M (2013) The changing racial dynamics of women's incarceration. Sentencing Project Washington, DC.

2. Roberts JM (2014) Collateral damage: America's failure to forgive or forget in the war on crime: A roadmap to restore rights and status after arrest or conviction.

3. Durose MR, Cooper AD, Snyder HN (2014) Recidivism of prisoners released in 30 states in 2005: Patterns from 2005 to 2010. Washington, DC: Bureau of Justice Statistics.

4. Bloom B, Owen B, Covington S (2004) Women offenders and the gendered effects of public Policy1. Review of Policy Research 21: 31-48.

5. Opsal T (2012) 'Livin'on the straights': Identity, desistance, and work among women Post-Incarceration. Sociological Inquiry 82: 378-403.

6. Covington SS, Bloom BE (2007) Gender responsive treatment and services in correctional settings. Women and Therapy 29: 9-33.

7. Kulkarni SP, Baldwin S, Lightstone AS, Gelberg L, Diamant AL (2010) Is incarceration a contributor to health disparities? access to care of formerly incarcerated adults. $J$ Community Health. 35: 268-274. [Crossref]
8. Arries EJ, Maposa S (2013) Cardiovascular risk factors among prisoners: an integrative review. J Forensic Nurs 9: 52-64. [Crossref]

9. Binswanger IA, Merrill JO, Krueger PM, White MC, Booth RE, et al. (2010) Gender differences in chronic medical, psychiatric, and substance-dependence disorders among jail inmates. Am J Public Health 100: 476-482. [Crossref]

10. Hughes TA, Wilson DJ (2003) Reentry trends in the united states. US Department of Justice. Bureau of Justice Statistics. Washington, DC.

11. Henrichson C, Delaney R (2012) The price of prisons: What incarceration costs taxpayers. Fed Sent'g Rep 25: 68-80.

12. Patel K, Boutwell A, Brockmann BW, Rich JD (2014) Integrating correctional and community health care for formerly incarcerated people who are eligible for medicaid. Health Aff (Millwood) 33: 468-473. [Crossref]

13. Modley P, Giguere R, Carter M (2010) Reentry considerations for women offenders Coaching packet.

14. Scroggins JR, Malley S (2010) Reentry and the (unmet) needs of women. J Offender Rehabil 49: 146-163.

15. Boehm PVV, Harvey A, Malloy D, Mestad R, Bush E, et al. (2005) Women offender transition and reentry: Gender responsive approaches to transitioning women offenders from prison to the community.

16. Fontaine J (2013) Examining housing as a pathway to successful reentry: A demonstration design process.

17. Nally J, Lockwood S, Ho T, Knutson K (2013) The marginally employed offender: A unique phenomenon among released offenders. J Correctional Education 64: 50-68.

18. Mauer M, McCalmont V (2013) A lifetime of punishment: The impact of the felony drug ban on welfare benefits. The Sentencing Project.

19. James DJ, Glaze LE (2006) Mental health problems of prison and jail inmates. Bureau of Justice Statistics Special Report.

20. Lejoyeux M, Adès J, Mourad S, et al. (1996) Antidepressant withdrawal syndrome CNS drugs 5: 278-292.

21. Brown CA, Hickey JS, Buck DS (2013) Shaping the jail inreach project: Program evaluation as a quality improvement measure to inform programmatic decision making and improve outcomes. J Health Care Poor Underserved 24: 435-443. [Crossref]

22. Bloom B, Owen BA, Covington S (2003) Gender-responsive strategies: Research, practice, and guiding principles for women offenders. National Institute of Corrections Washington, DC.

23. Texas Board of Criminal Justice (2014) Texas department of criminal justice statistical report FY 2014. Texas Department of Criminal Justice.

24. Maruschak LM, Bronson J (2017) HIV in prisons 2015 statistical tables. (NCJ 250641) US Department of Justice: Bureau of Justice Statistics.

Copyright: (C2018 Raber M. This is an open-access article distributed under the terms of the Creative Commons Attribution License, which permits unrestricted use, distribution, and reproduction in any medium, provided the original author and source are credited. 